\title{
A PROSPECTIVE OBSERVATIONAL STUDY ON THE INCIDENCE OF DRUG-RELATED HOSPITAL ADMISSIONS IN A TERTIARY CARE HOSPITAL
}

\author{
AKSHAY TL*, ALAKA PRAKASH, ASHIQ MOHAMED ANAS M, DIWAHAR S, RAMA P
}

Department of Pharmacy Practise, PSG College of Pharmacy, Coimbatore, Tamil Nadu, India. Email: akshaytl000@gmail.com

Received: 03 December 2020, Revised and Accepted: 13 February 2021

ABSTRACT

Objectives: The objective of the study is to identify the incidence of drug-related problems coming to the EMD, classify, and identify the risk factor for DRP.

Methods: This was a prospective observational study conducted in the emergency department for a period of 6 months. The patients admitted through EMD with DRP were identified and then were classified according to Hepler and Strand, 1990 and Classen et al., 1997.

Results: A total of 109 patients were identified with DRP in our study. Among them, major part was contributed by ADRs (69.7\%), non-adherence $(27.5 \%)$ followed by sub-therapeutic dosage, and untreated indication and overdosage $(0.91 \%)$. The major organ system involved in DRPs was found to be neurological system (26.60\%) and gastrointestinal system (23.85\%). The major causative drug class for DRP was found to be anti-thrombotic agents (27\%), and the major risk factor for the development of DRP was found to be polypharmacy.

Conclusion: Drug-related problems are becoming one of the major reasons for the EMD admissions in the hospitals. It can cause significant burden to the society and to the health of the people.

Keywords: Drug-related problems, Emergency admissions, Incidence, ADR, Non-adherence.

(c) 2021 The Authors. Published by Innovare Academic Sciences Pvt Ltd. This is an open access article under the CC BY license (http://creativecommons.org/ licenses/by/4.0/) DOI: http://dx.doi.org/10.22159/ajpcr.2021v14i4.40444. Journal homepage: https://innovareacademics.in/journals/index.php/ajpcr

\section{INTRODUCTION}

When people use medication, any number of outcomes is possible. Most commonly, the patient benefits from the pharmacotherapeutic interventions; however, there is only a fine line of distinction between the anticipated outcome and side effect of the drug. Any deviation from the intended beneficial effect of medication can result in drug-related problem (DRP) [1]. Nowadays, the problems related to drugs represent a major cause of morbidity and are thought to cause between $10 \%$ and $30 \%$ of all hospital admissions in elderly patients [2].

DRPs pose a challenge to the physician, pharmacist, and other healthcare professional since it alters the expected therapeutic outcome. Furthermore, it increases the health-care costs of the patient. Estimates have shown that for every US $\$ 1$ spent on drugs, US $\$ 1.33$ is consumed to treat DRPs [3]. Since the economic impact of DRPs is high, it is important to identify and resolve them. To do that, it is important to categorize the DRPs. There are 8 major types of DRPs that have been identified.

Adverse drug reaction which is the most common DRP is defined as "any response that is noxious and unintended and that occurs at doses normally used in humans for prophylaxis, diagnosis, or treatment, excluding a failure to accomplish the intended purpose. A drug interaction is "a medical problem resulting from a drug-drug, drug-food, or drug-laboratory interaction"; drug non-compliance "the extent to which the patient's drug-taking behavior (in terms of taking medication) coincides with the prescription" [4]; failure to receive drugs is a "medical problem that resulted from not receiving a drug" (e.g., for pharmaceutical, psychological, sociological, or economic reasons); improper drug selection was the taking of a wrong drug (other than one prescribed by the physician); drug overdose was a medical problem treated with too much of the correct drug (toxicity); and untreated indication was a medical problem that required drug therapy (an indication for drug use), but for which the patient was not receiving a drug.
Corrective, preventive, and educational strategies should concentrate on the most frequently reported populations, diseases, and medications. The study addresses the proper use of medications to ensure the best outcomes of pharmacological interventions.

\section{METHODS}

This prospective cohort observational study was conducted at the EMD in PSG Hospital, Coimbatore. The study was carried out over a period of 6 months from February to July 2019 and was approved by the Institutional Ethics Committee at PSG.

A sample of 1000 patients was selected and observed. A patient is included if admitted through EMD due to DRPs during the study period. The data were collected to determine the incidence of admissions through the EMD due to DRPs, identify them, and to classify them based on strand et al. classification mentioned earlier. The study also involved the understanding of major organ system involved in the DRP, major causative drug, and the major risk factor for DRPs. The statistical significance was calculated using odds ratio $\left({ }^{*} \mathrm{p}<0.05\right)$.

\section{RESULTS}

During the study period, 1000 patients were recruited for the study, and among those patients, 109 were found to be admitted through EMD with drug-related problems.

\section{Incidence}

Incidence is the measure of probability of occurrence of a given medical condition in a population with a specified period of time. The incidence of DRPs in our study was found to be $10.9 \%$.

Categorization of DRPs as per hepler and strand classification The Hepler and Strand classification classifies the DRPs into 8 categories. In our study, the 109 DRPs had 5 categories. The DRP most experienced by the patients was found to be ADR 76 (69.7\%) followed by non- 
adherence 30 (27.5\%). Untreated indication, sub-therapeutic dose, and overdosage were found one case each (0.91\%) (Table 1 and Fig. 1).

\section{ADRS and its incidence}

Of the 109 DRPs found, 76 of them were found to be ADRs. It constituted the major part of the DRPs from EMD.

The likelihood of the DRP due to ADR was assessed using Naranjo scale. In that, $6.42 \%$ were definite, $39.44 \%$ were probable, $22.01 \%$ were possible, and $1.83 \%$ was found to be doubtful (Fig. 2).

\section{Gender-wise distribution of ADR and non-adherence}

A total of 76 males (69\%) and 33 females (31\%) were found to have DRPs during the study.

It was found that male patients had more ADRs (63.1\%) than females $(36.8 \%)$, and cases of non-adherence were also more in the cases of males (60\%) than in females (40\%) (Fig. 3).

The association of the gender with the occurrence of DRPs was calculated with the odds ratio formula. It was found that there was significant association between the occurrence of DRP and gender $\left({ }^{*} \mathrm{p}<0.005\right)$.

\section{System most affected by DRPs}

Of the 109 DRPs found in the study, it was found that the organ system most involved in DRP was neurology system (26.60\%), gastrointestinal system (23.85\%), immunology system (13.76\%), nephrology system (10.1\%), hematology system $(8.25 \%)$, endocrinology system $(7.33 \%)$, and cardiovascular system (5.50\%).

Table 1: Organ systems most affected due to DRPs

\begin{tabular}{llll}
\hline S. No. & System & Number & Percentage \\
\hline 1. & Hematology & 9 & 8.25 \\
2. & Nephrology & 11 & 10.1 \\
3. & Gastrointestinal & 26 & 23.85 \\
4. & Endocrinology & 8 & 7.33 \\
5. & Neurology & 29 & 26.60 \\
6. & Rheumatology & 1 & 0.91 \\
7. & Immunology & 15 & 13.76 \\
8. & Psychiatry & 2 & 1.83 \\
9. & Cardio vascular & 6 & 5.50 \\
10. & Others & 2 & 1.83 \\
\hline
\end{tabular}

Age-wise distribution of DRPS

About 1000 participants were enrolled in this study. In that, the age groups were classified into 3 major categories. Group 1 included participants from age 0 to 18 , Group 2 included participants of age between 19 and 60, and Group 3 consisted of participants with age above 60 . In our study, it was found that the most number of DRPs occurred in Group 2 (19-60) followed by Group 3 (>60) (Fig. 4).

The association of the occurrence of DRP with age groups was calculated and it was found to be not significant $\left({ }^{*} \mathrm{p}>0.05\right)$.

\section{DRPs and comorbid conditions}

The occurrence of DRP is closely associated with the presence of comorbid conditions. It was found that a significant higher risk of DRPs in patients with comorbidities. The major comorbid conditions found in patients with DRPs were T2DM (28.5\%), HTN (31.4\%), and DLP (20\%) (Table 2).

Association of comorbidities with DRPs was calculated using odds ratio, and it was found to have a significant association with the occurrence of DRPS $\left({ }^{*} \mathrm{p}<0.05\right)$

\section{DRPs and polypharmacy}

In our study, of the 1000 patients studied, 588 patients were taking more than one medication (polypharmacy), and from the 109 patients with DRPs, 30 patients were found to have polypharmacy.

The association of polypharmacy with the occurrence of the DRPs was checked using odds ratio.

The $p$ value for this was found to be significant $\left({ }^{*} p<0.05\right)$, so polypharmacy was found to be a significant risk factor for DRPs.

\section{DRPs and alcohol}

Alcohol was taken as a risk factor for the development for DRP. In our study, on 1000 patients, it was found that 102 patients had alcohol as a risk factor, and in that, 7 patients were found to have developed DRP.

The association of the DRP was calculated and was found to be significant with the help of odds ratio and it was found that there was no significant association for alcohol with that of DRPs $\left({ }^{*} p>0.05\right)$.

\section{Drugs associated with the DRPs}

The most common drug groups associated with DRPs were antithrombotic agents (27\%); antihypertensive (15\%); antibiotics

Table 2: List of comorbidities found in the patients

\begin{tabular}{|c|c|c|c|c|c|}
\hline S. No. & Conditions & Comorbidities in patients with DRP & Percentage & Comorbidities in patients with NDRPs & Percentage \\
\hline 1 & T2DM & 20 & 28.5 & 95 & 9.69 \\
\hline 2 & HTN & 36 & 51.4 & 107 & 11.09 \\
\hline 3 & DLP & 14 & 20 & 20 & 2.02 \\
\hline
\end{tabular}

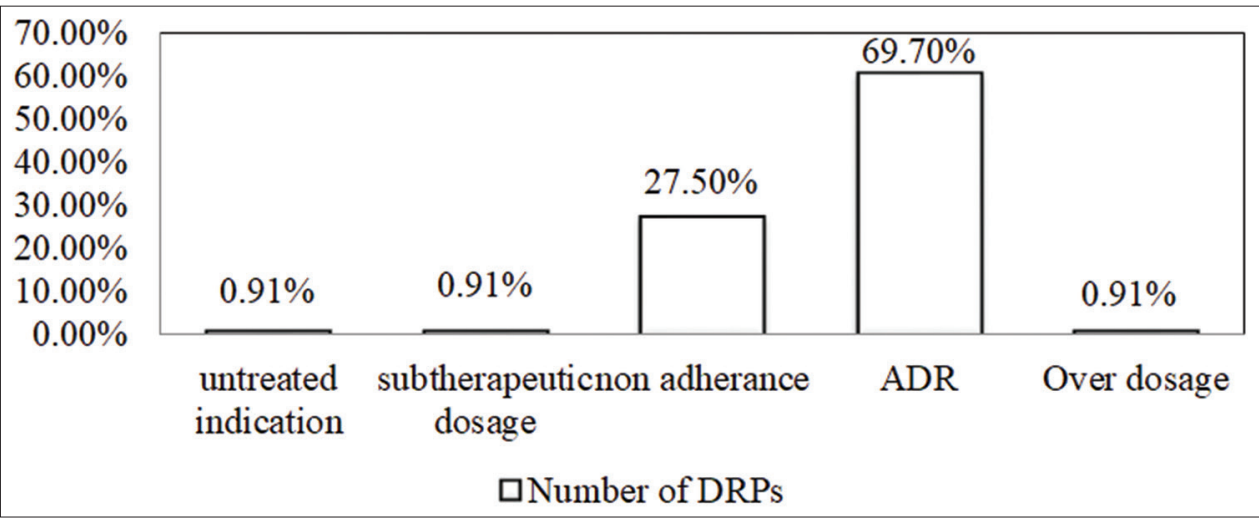

Fig. 1: Types of DRPs that occurred in patients 


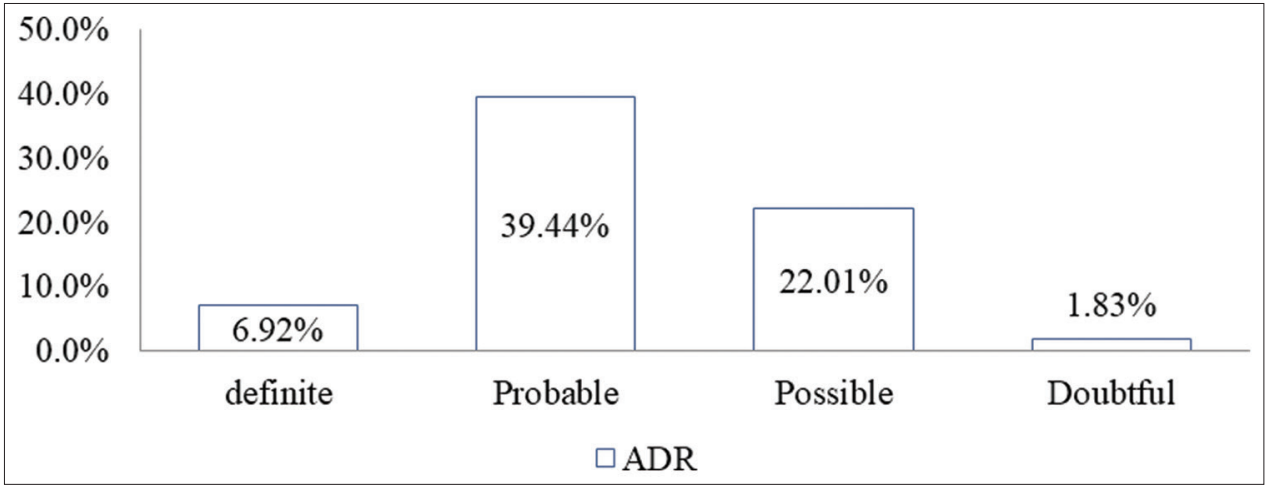

Fig. 2: Likelihood of ADR

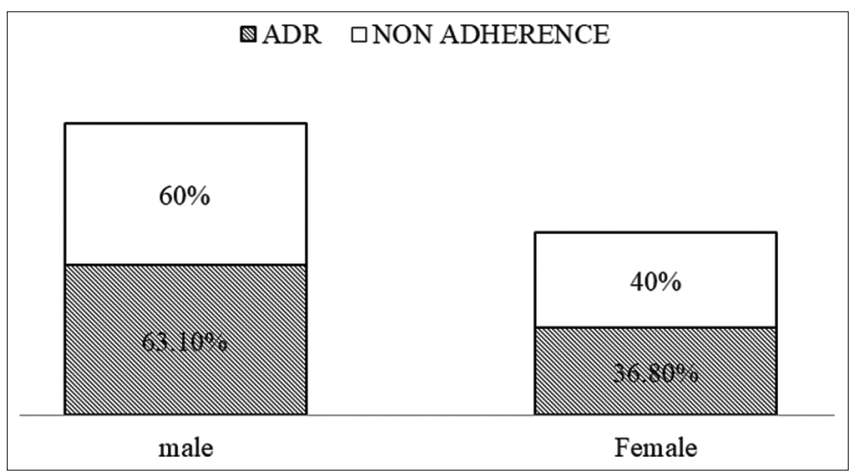

Fig. 3: Occurrence of ADR and non-adherence in males and females

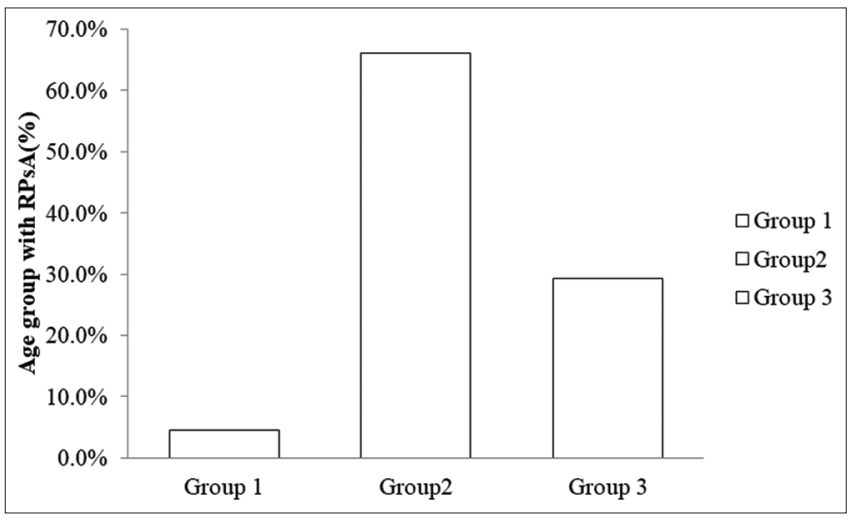

Fig. 4: Distribution of DRPs in various age groups

(12\%); anti-TB agents (9\%); steroids (8\%); immunosuppressant's (5\%); antidiabetic, antiretroviral agents, and antipsychotic agents (4\%); antithyroid agents and NSAIDs (3\%) followed by oral contraceptives $(1 \%)$; antigout agents (1\%); PPIs (1\%); opioids (1\%); anticonvulsants (1\%); and antidepressants (1\%) (Fig. 5).

\section{Outcomes associated with DRPs}

The outcome most associated with DRP was found to be CVA and seizures $(11.92 \%)$, rashes $(11 \%)$, bleeding $(9.17 \%)$, and gastritis $(7.33 \%)$. Most of the outcomes were due to the ADRs and non-adherence to the medications and most of them were preventable (Table 3).

\section{DISCUSSION}

Drug-related visits to the ED constitute a significant problem that contributes to the overall pressure on our health-care system. In our study, the incidence of DRP in 1000 patients admitted through EMD was
Table 3: Diagnosis associated with DRPs

\begin{tabular}{lllll}
\hline S. No. & Diagnosis & Number & Percentage & DRP \\
\hline 1. & Diarrhea & 1 & 0.91 & ADR \\
2. & CVA & 13 & 11.92 & $\begin{array}{l}\text { ADR, NA, } \\
\text { untreated } \\
\text { indication }\end{array}$ \\
& & & & ADR \\
3. & Hypokalemia & 3 & 2.75 & ADR \\
4. & Ataxia & 1 & 0.91 & ADR \\
5. & neurotoxicity & 1 & 0.91 & ADR \\
6. & Cholestasis & 1 & 0.91 & NA \\
7. & Schizophrenia & 1 & 0.91 & ADR \\
8. & Fall & 2 & 1.83 & ADR \\
9. & Liver Injury & 4 & 3.66 & ADR \\
10. & Depression & 2 & 1.83 & NA \\
11. & Hemolytic Anemia & 4 & 3.66 & ADR \\
12. & RV Infection & 1 & 0.91 & ADR \\
13. & Flu-like syndrome & 1 & 0.91 & ADR \\
14. & Hyperkalemia & 3 & 2.75 & ADR \\
15. & Headache & 1 & 0.91 & \\
16. & Leukopenia & 1 & 0.91 & \\
17. & Thrombocytopenia & 2 & 1.83 & \\
\hline & & & &
\end{tabular}

checked and it was about $10.9 \%$ of the population. Many DRP-based retrospective studies identified them in the range of $0.86-10.6 \%$ [5]. Strand et al. classified DRP into eight categories focusing more on DRPs themselves than on why they occur. The most commonly presented DRPs were adverse drug reactions or side-effects of drugs as well as non-adherence to drugs such as antibiotics [6]. In our study, it was found that ADRs and non-adherence to antiepileptics caused the most number of DRPs. Adverse drug reactions can have major impacts with several meta-analyses reporting around $5 \%$ of admissions due to ADRs [6]. In our study, ADR was the most occurring DRP found with almost 76 cases to support. The system most affected by ADRs was found to be GI system (47.5\%) followed by immune system [7,8]. Our study showed that neurological system was the most affected due to DRPs followed by gastrointestinal system.

Specific risk factors facilitate the occurrence of DRP. Various studies have determined numerous risk factors for DRPs. Females, polypharmacy, administration of drugs with narrow therapeutic range, age $>65$, use of oral anticoagulants, and diuretics, where identified as relevant risk factors for ADEs and ADRs [9]. In our study, polypharmacy, alcohol, comorbid conditions, use of anticoagulants, and diuretics were found to have serious effects on patients' health which caused EMD admissions. Polypharmacy is a concern in this group because there are age-related physiological changes that alter the ways in which drugs are handled by the body. These may include reduced renal function, reduced liver function, reduced ratio of body fat to water, and delayed stomach emptying. Our study showed that there was a statistically significant association between polypharmacy and occurrence of DRPs which was 9 times higher than in patients without polypharmacy (9.125). At 


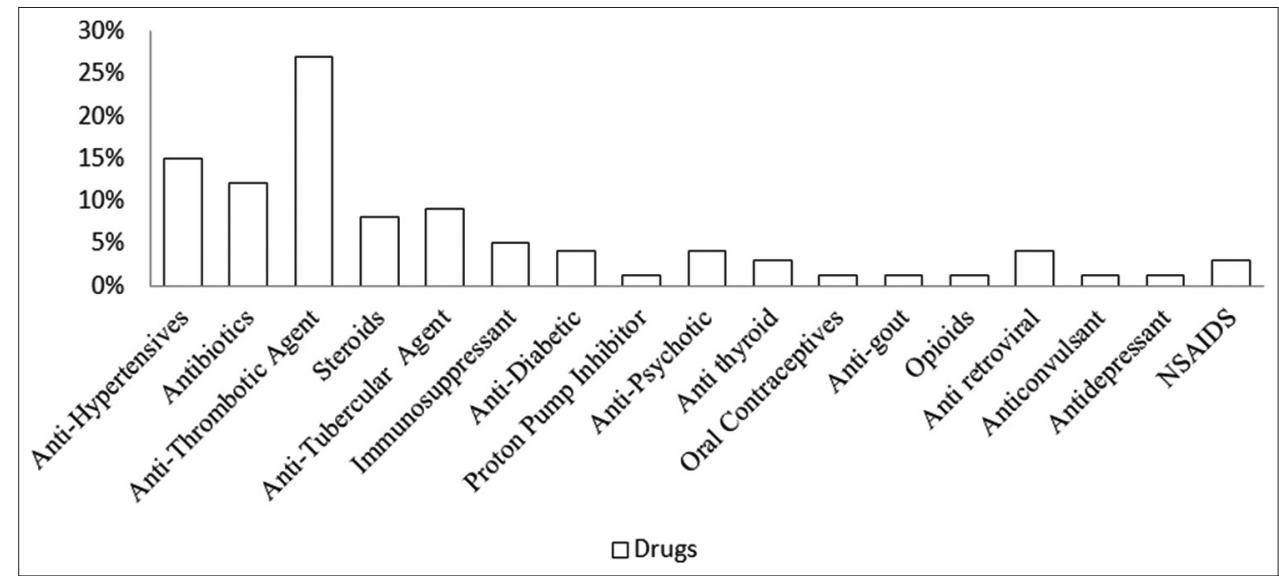

Fig. 5: Drugs associated with DRPs

dynamics level, alcohol enhances the deleterious effects of sedatives, certain anxiolytics, antipsychotics, and anticholinergic agents [10]. On evaluation, 7 of 109 DRP cases had alcohol as risk factor. Our study does not support the fact that there is significant association between alcohol use and occurrence of DRP. The most common diagnosis associated with DRPs was seizures $(11.9 \%)$, stroke $(11.9 \%)$, rashes $(11 \%)$, bleeding $(9.17 \%)$, gastritis $(7.33 \%)$, hyperglycemia $(3.66 \%)$, edema $(3.66 \%)$, and liver injury (3.6\%). There is no significant difference between male and female group with respect to identify DRPs.

\section{CONCLUSION}

Drug-related problems have become a common problem for hospitalization these days. DRP poses a challenge to the clinician and that may affect the patient's clinical outcome. Most of the DRPs were found in the adult population (19-60) admitted through EMD.

Majority of the DRP was contributed by ADR (69.7\%) followed by noncompliance $(27.5 \%)$ to the drug therapy.

The major causative drug class found to cause DRP was antihypertensive and anticoagulants, followed by antibiotics, steroids etc. The organ system which was most affected was found to be gastrointestinal system. The major risk factors associated with DRP were found to be presence of comorbid conditions such as T2DM, HTN, DLP, and other factors such as alcohol consumption, polypharmacy etc.

The role of clinical pharmacist is much appreciated in managing DRPs. Designing one-to-one education strategies to improve medication adherence and management of ADRs can be helpful in getting a positive drug therapy outcome. A clinical pharmacist through his/her clinical accuracy can identify the DRPs early and come up with suitable solutions to resolve them. Thereby, reducing the burden of illness on the patients and the health-care costs and also resulting in a successful drug therapy.

\section{ACKNOWLEDGEMENT}

We are thankful to PSG Institute of Medical Science and Research for giving us the opportunity to perform the study. We also thank Dr Rajesh Shankar Iyer MD, DM, Department of Neurology and medical staffs of PSG Hospitals, Coimbatore, Tamil Nadu, for their constant support throughout the study.

\section{LIMITATIONS}

A significant number of patients with minor DRPs have been missed from the outpatient department and other major departments since we focused on the patients admitted through emergency department only.

\section{AUTHORS CONTRIBUTION}

Alaka Prakash conceptualized the research idea, performed literature search, and wrote the manuscript. Akshay T.L edited the manuscript, Ashiq Mohamed Anas and S.Diwahar revised the manuscript, and P.Rama guided throughout the research and acted as the corresponding author.

\section{CONFLICTS OF INTEREST}

The authors declare that there are no conflicts of interest.

\section{FUNDING}

This research did not receive any specific grant from funding agencies in the public, commercial, or non-for-profit sectors.

\section{REFERENCES}

1. Johnson JA, Bootman JL. Drug-related morbidity and mortality. A costof-illness model. Arch Intern Med 1995;155:1949-56.

2. Royal S, Smeaton L, Avery AJ, Hurwitz B, Sheikh A. Interventions in primary care to reduce medication related adverse events and hospital admissions: Systematic review and meta-analysis. Qual Saf Health Care 2006;15:23-31.

3. Busto U, Naranjo CA, Sellers EM. Comparison of two recently published algorithms for assessing the probability of adverse drug reactions. Br J Clin Pharmacol 1982;13:223-7.

4. Al-Arifi M, Abu-Hashem H, Al-Meziny M, Said R, Aljadhey H. Emergency department visits and admissions due to drug related problems at Riyadh Military Hospital (RMH), Saudi Arabia. Saudi Pharm J 2014;22:17-25.

5. Nair NP, Chalmers L, Peterson GM, Bereznicki BJ, Castelino RL, Bereznicki LR. Hospitalization in older patients due to adverse drug reactions -the need for a prediction tool. Clin Interv Aging 2016;11:497505.

6. Easton-Carter KL, Chapman CB, Brien JE. Emergency department attendances associated with drug-related problems in paediatrics. $\mathrm{J}$ Paediatr Child Health 2003;39:124-9.

7. Kourorian Z, Fattahi F, Pourpak Z, Rasoolinejad M, Gholami K. Adverse drug reactions in an Iranian department of adult infectious diseases. East Mediterr Health J 2009;15:1351-7.

8. Krähenbühl-Melcher A, Schlienger R, Lampert M, Haschke M, Drewe J, Krähenbühl S. Drug-related problems in hospitals: A review of the recent literature. Drug Saf 2007;30:379-407.

9. Hohl CM, Dankoff J, Colacone A, Afilalo M. Polypharmacy, adverse drug-related events, and potential adverse drug interactions in elderly patients presenting to an emergency department. Ann Emerg Med 2001;38:666-71.

10. Laisi U, Linnoila M, Seppälä T, Himberg JJ, Mattila MJ. Pharmacokinetic and pharmacodynamic interactions of diazepam with different alcoholic beverages. Eur J Clin Pharmacol 1979;16:263-70. 